\title{
RESENHA: Global gay. Cómo la revolución gay está cambiando el mundo
}

\author{
Amaral Palevi Gómez Arévalo \\ amaral.palevi@gmail.com
}

\section{Resenha: MARTEL, Frédéric. 2014. Global gay. Cómo la revolución gay está cambiando el mundo. $1^{a}$ ed. Lima: Taurus, 330 p.}

Frédéric Martel, sociólogo francés, por medio de un estudio en 45 países por cinco años nos presenta en su libro Global Gay (2014), una visión general de lo que acontece en regiones del mundo distantes entre sí, pero unidas por la presencia de hombres con sexualidades disidentes a la norma binaria heterosexual, a los cuales en los países de cultura occidental se les denomina como: gay, mas, esa definición no es la única, no es hegemónica, existen conceptos, que al igual que la palabra gay o queer han sido apropiados y resignificado por las comunidades, movimientos, organizaciones, movidas o simplemente por activistas que en la visibilidad, la marginalidad o la clandestinidad luchan por construir un mundo más justo $\mathrm{y}$ tolerante que respete los Derechos Humanos sin importar cualquier marcador social diferenciador en los seres humanos.

Global Gay, es un dialogo fluido que Martel establece con una serie de entrevistados en los Cinco Continentes. En sus propias palabras, uno de los objetivos de este libro es "dar la palabra a esos militantes valientes «ordinarios», que en realidad son extraordinarios" (p. 23), en el sentido que muchos de ellos y ellas viven en circunstancias límites que les coloca en peligro de vida, ante sistemas ya sea culturales o políticos represivos, sobre todo en los 14 países musulmanes donde las prácticas sexuales entre personas del mismo sexo son condenadas a muerte. Aunque ésta condición es lo más extremo, Martel nos presenta que también en países no musulmanes, tanto en el Occidente, Oriente o en el Hemisferio Norte o Sur, las personas que ejercen prácticas sexuales contra las normas binarias heterosexistas pueden ser objeto de daños físicos, psicológicos, económicos, e inclusive puede conducir a la muerte, tanto en forma de suicidio como de homicidio.

La tarea que Martel emprende en Global Gay es analizar los procesos de globalización a través del prisma de la cuestión gay, ejerciendo un activismo por medio de la investigación de una geopolítica de la sexualidad, una descripción de la política sexual al interior de varios países, una clasificación de los territorios que ocupan las minorías sexuales, un análisis de clases sociales, los medios de comunicación, imaginarios colectivos de las comunidades de homosexuales, la cuestión de construcción de una identidad, el activismos y sus diferentes formas de manifestación, y por último los procesos comerciales y sus conexiones con el movimiento gay.

La geopolítica de la sexualidad, es posiblemente el eje más sobresaliente en todo el desarrollo de la obra. Martel, presenta una clara división de los países por medio de la integración, aceptación, tolerancia o rechazo a la cuestión gay. Como primer punto, coloca a Europa, Estados Unidos y los países de América Latina donde la aceptación es más común y la tolerancia está en aumento. En Europa existe el Intergrupo para los derechos LGBT en el parlamento europeo el cual se encarga por dar seguimiento a los temas gays, lésbicos, bisexuales y trans (LGBT) en la Unión Europea. Sobre Estados Unidos lo que más hace notar Martel es el accionar de 
fundaciones y ONG que ejercen una decidida influencia a nivel local, nacional e internacional sobre temáticas LGBT.

Por otra parte los países de América Latina son colocados a manera de ejemplo de esa tolerancia en aumento por medio de la expresión: "el despertar gay" (p. 51). Esta percepción la concluye por medio de las visitas realizadas a México, Colombia, Brasil, Argentina, Cuba y Venezuela. No obstante, menciona que existe "retraso" (p. 208) en otros, de los cuales deseo resaltar los países de Centroamérica, sobre todo en Nicaragua, El Salvador y Honduras, de los cuales no aborda mayor información. Por tal razón considero necesario realizar matices en el desarrollo del discurso de lo que sucede en El Salvador como un aporte para enriquecer la mirada que propone Martel en Global Gay.

Entre las zonas geográficas que entablan públicamente un rechazo a la cuestión gay encontramos a Europa del Este que incluye Rusia, África, Asia, el Asia musulmana y todo el Oriente Próximo musulmán. El Oriente Próximo musulmán es la región donde la propia vida de los homosexuales está en riesgo. Respecto al Asia musulmana, existe una diferenciación al ser un islam asiático más condescendiente, aunque se debe de aclarar que "la ausencia de leyes antigays no se traduce necesariamente en una mayor tolerancia" (p. 159). En algunos países de Asia se aplica una trilogía de penalización jurídica, desaprobación social y no aplicación de la ley por parte de la policía. En China la homosexualidad, no se aprueba, no se desaprueba y no se promueve. Se desconoce la situación de los derechos de los gays en el Asia Central, en las ex repúblicas soviéticas. En este punto el autor, con las palabras de un activista japonés, afirma que los derechos de los homosexuales no es una cuestión de oriente ni de occidente, es universal.

En el caso de los países de África, existe una geopolítica de la sexualidad influenciada por la lengua colonial de uso. Así una mayoría de los países francófonos son políticamente más tolerantes, en cambio los anglófonos son perseguidores de los gays, tanto por políticos populistas como por religiosos, lo que el autor denomina "Caza de homosexuales en África". Evidencia el accionar de la evangelización que iglesias ultraconservadoras estadounidenses realizan en países de África (p. 187), y así la cuestión gay en algunos países camina entre los peligros del neoevangelismo cristiano y el islamismo político. Una contradicción en los países africanos, y tal vez un modelo a nivel político, es la situación de Sudáfrica, la cual en 1994 incorpora la prohibición de discriminación por orientación sexual en su Constitución.

En los países del Este de Europa, y por la influencia que ejerce sobre estos, se incluye a Rusia, donde la cuestión gay es vista como un fenómeno social occidental, aunque se conoce que la homosexualidad ha estado presente en Rusia por los menos desde Chaikovski (165). Como proceso de diferenciación y nacionalismo se niega cualquier tipo de prerrogativa que vaya en función de la promoción de los derechos humanos de las personas gays. Creando el siguiente axioma: "Oeste desviado, Este normal" (p. 167).

También se analiza el modelo nórdico de integración. Este modelo se caracteriza por la despenalización rápida de la homosexualidad en el siglo pasado, reconocimiento de las uniones civiles, matrimonio igualitario y la primera jefa de Estado casada con una persona de su mismo sexo.

Esta división de la geopolítica de la sexualidad queda mejor definida en la narración sobre la Declaración relativa a los derechos humanos y a la orientación sexual y la identidad de género, realizada el 18 de diciembre de 2008 en la sede de la Organización de las Naciones Unidas (ONU). 
La Declaración es presentada por Argentina y cuenta con el apoyo de Brasil, Francia, Croacia, Gabón, Japón, Noruega y Países Bajos. Ante esta declaración se adhieren sesenta y seis países de los cinco continentes, a los cuales se suman posteriormente Estados Unidos y Costa Rica. Pero al mismo tiempo se presenta una contra declaración presentada por Siria e impulsada por la Organización de la Conferencia Islámica (OCI), que cuenta con el apoyo de cincuenta y nueve países, incluido el Vaticano que se fundamentaron en que la orientación sexual no tiene base legal en el sistema de Naciones Unidas. Sesenta y ocho países no apoyan ninguna declaración, de los cuales llama la atención el caso de Sudafrica, que bajo el liderazgo de Jacob Zuma no quiso ser un punto diferenciador en África, aunque esto supone estar contrarios a su Constitución política.

Con base a esa diferenciación geopolítica se establece el marco de la política sexual al interior de los países. Por una parte en donde la aceptación y tolerancia es mayor las metas están trazadas para el ejercicio pleno de los Civil Rights (p. 87), los Derechos Humanos y el Same-sex marriage como punto angular en el debate sobre los derechos de los gays en Occidente (p. 91). La política sexual de gays se está implementando por medio de grupos de presión, grandes organizaciones y fundaciones, tema que abordaremos más adelante. No obstante, los Derechos Humanos de personas gays en países del Occidente no solamente se gestan enfrente de los políticos, sino que también son incluidos los medios de comunicación, fundaciones, escuelas, iglesias y empresas, sobretodo en estas últimas por su relevancia para derechos fundamentales como la protección social y asistencia sanitaria.

Respecto al derecho del matrimonio, al contrario de lo que los conservadores opinan que se pretende "redefinir el matrimonio", en realidad lo que las personas LGBT deseamos es "poner fin a una discriminación" (p. 106), tal como aconteció en Massachusetts. El Tribunal Supremo de Massachusetts, obliga por primera vez a un estado de Estados Unidos a reconocer el derecho al matrimonio a todas las parejas, sea cual sea su sexo por medio de la decisión llamada "Goodridge", el 18 de noviembre de 2003 (p. 97). Esta decisión abre la puerta para la realización de procesos similares en otros Estados, e incluso pudo influenciar a países de América Latina para hacer efectivo ese Derecho. De igual forma también fue el detonador para sectores conservadores proponer legislaciones que prohíban el matrimonio a personas del mismo sexo, como el caso de El Salvador. En el año 2003 se presenta una primera reformar constitucional para otorgar el derecho al matrimonio solamente a hombres y mujeres así nacidos e impedir la adopción por personas del mismo sexo. En el año 2006 continúa esa lucha. En el año 2009 vuelve a ser tema de discusión que se extrapola a varios sectores de la sociedad, en donde el partido mayoritario de izquierda en el último momento para ratificar esa reforma, niega sus votos. En Abril del año 2015 nuevamente el bloque conservador de derecha y evangélicos fundamentalista aprueban nuevamente la reforma y se está a la espera de una segunda votación en el nuevo periodo legislativo que inició el $1^{\circ}$ de mayo de 2015.

En otros países donde el rechazo a toda expresión de lo gay es la norma, se está luchando por una visibilidad como meta. En estos países la provocación resulta contraproducente y no permite avanzar en los derechos concretos de los homosexuales. Así se procura formas diferentes para ejercer influencia, por ejemplo en Rusia se necesita aliarse a otros movimientos sociales, incluso cuando algunos de estos son hostiles a la causa gay, pero es necesario para una ampliación de la fuerza en las demandas por reconocimiento político ante el Estado. La 
política sexual se ha orientado a una política pragmática de alianzas con otros movimientos sociales de protesta.

En los países donde las prácticas sexuales entre personas del mismo sexo son penalizadas, se intenta promover una política sexual de las "Libertades privadas" (p. 273), en las cuales, según la palabras de un entrevistado: "Siempre que sea discreto, es mucho más fácil para un joven iraní ser gay que ser heterosexual" (p. 268), dadas las prohibiciones religiosas entre hombres y mujeres. En el África austral el combate al VIH, es sinónimo de combate a los homosexuales.

Aunque por paradójico o contradictorio que parezca en los contextos diferentes estudiados el Islam, la Iglesia Católica, la Iglesia Ortodoxa y los evangélicos comparte su intolerancia hacia la homosexualidad.

Una diferencia entre la política sexual tan impulsada en Occidente del Coming out como punto de partida para la lucha política, en otros países acontece un coming home como acción política concreta que se contextualiza en la tradición cultural de algunos países asiáticos con influencia del confucionismo. En países de influencia musulmana es el Questioning, el aprendiendo a ser gay (p. 16) la política sexual predomínate. Por último, en algunos países la politización de una identidad gay no es clara, o incluso no es deseada, ya que la homosexualidad se remite a una práctica más que a una identidad, y la diversión resulta ser más importante que la defensa de los derechos humanos.

Respecto a los marcadores sociales de "la raza y la clase social son a menudo factores mucho más determinantes que la orientación sexual" (p. 180). Esta situación se evidencia en los 45 países que se realiza la investigación, dado que se expone una ecuación simple bajo estos tres ítems: 1) Ser pobre y gay: discriminación, 2) Ser clase media y gay: tolerancia, y 3) Ser rico y gay: indiferencia. Así por ejemplo en la China rural se presentan matrimonios concertados y miseria de los gays sin posibilidad de mudarse por falta de un pasaporte interno que les dé el derecho de trasladarse del campo a la ciudad (p. 121). La vivencia de una vida homosexual discreta de hombres de clase media en países donde es penalizada o rechazada esa práctica, es la forma de vida que asumen muchos homosexuales.

En el ámbito de América Latina, la apertura de lo gay, tiene una relación directa con el ascenso de los gays a las clases medias urbanas, como la clase $\mathrm{C}$ brasileña emergente, $\mathrm{y}$ en forma de media verdad y media broma, lo que se expresa en Bogotá sobre la maricocracia, la cual se refiere al ascenso y visibilidad de los gays de clase media. Este ascenso también conlleva la reproducción de patrones de discriminación, en este caso el racismo tiende acentuarse en la comunidad gay. Un análisis de lo rural no se presenta, siendo un tema al cual se debe dar mayor atención.

Respecto a los territorios, Global Gay presenta una interesante clasificación de los lugares que ocupan los gays. Se tiene que destacar que existe una hegemonía de lo urbano en esta clasificación. Esta situación puede deberse a que los gays encuentra mayores facilidades para visibilizarse en los espacios urbanos que aquellos otros más rurales. El segundo punto a destacar que la mayor parte de esta clasificación se origina en el estudio de barrios y ciudades en Estados Unidos, pero a los cuales se pueden realizar paralelos con otras ciudades de diferentes países.

La clasificación inicia por el mítico gueto, el cual es un enclave gay principalmente nocturno, cerrado y algunas veces protegido. De ahí se da paso a los Barrios Gays (gayborhoods) (p. 42) siendo locales diseminados por un territorio específico en la 
periferia de la ciudad con una presencia importante de gays y comercios para este público. Lo que sigue es el agrupamiento (cluster), siendo locales concentrados en un sector, uno junto al otro, con una identidad pragmática comercial, más que residencial. La Cinta (strip) es la forma de referirse a la ocupación de los locales gays uno junto al otro a lo largo de una gran avenida (p. 43). También existe la Colonia, como esas zonas de veraneo, balnearios o ínsulas que son ocupadas mayoritariamente por personas gays como lugar de residencia (p. 43). La clasificación de Village, que hace referencia a un agrupamiento de varios locales gays en un pequeño territorio en los centros históricos de las ciudades, con identidad urbana y cultural (p. 43). Por último se encuentra la dispersión (sprawl), en la cual la residencia y los locales gays se integran en los diferentes barrios de una ciudad (p. 45).

Respecto a Latino América, la distribución geográfica de los gays es variada. En el caso de Cuba, en las casas particulares y habitaciones se privatiza la vida gay, en contra posición México y Brasil en sus grandes centros urbanos, existe barrios y sectores que los gays se han apropiado, como la Zona Rosa y la Calle República de Cuba en México D. F., la Playa de Ipanema en Rio de Janeiro, o en los alrededores del Largo do Arouche, en São Paulo (p. 49), y Buenos Aires, la Martel clasifica como la capital gay de América Latina, dado que no hay un barrio específico gay y toda la ciudad parece ser gay friendly (p. 53). En San Salvador, se presenta un modelo de dispersión de los locales gays, debido a las condiciones de intolerancia y las condiciones económicas. Siendo un punto de cuestionamiento a la conclusión que Martel explicita sobre la distribución geográfica de lo gay: "cuando más gay friendly es una ciudad, más disgrega la vida gay y se disuelve en el tejido urbano; cuanto más frágil es la tolerancia, más tiende la vida gay a agruparse en villages y cluster".

Los comercios LGBT en los contexto occidentales "sus comercios pasan del gueto al hit" (p. 23). Este éxito comercial ha promovido un tipo de militancia gay mercantil por medio de la venta de artículos con emblemas o símbolos representativos de la comunidad LGBT. En otros contextos, a falta de espacios, se ocupan algunos contra la propia voluntad de los administradores y gerentes como el caso de Cuba en su célebre Malecón y la esquina de la Calle 23. La presión comercial hace que la vida gay en los países emergentes sea una revelación (163). Incluso el turismo sexual gay, que no cuestiona las lógicas hegemónicas, moviliza a la visibilidad de la vida gay en diferentes países.

Respecto a los medios de comunicación en este momento se está gestando diferentes 'guerras culturales' a nivel global, una de estas es la emprendida por los evangélicos en Estados Unidos. Las iglesias neoprotestantes han desarrollado una capacidad extraordinaria de movilización mediática de alto impacto en seguidores fundamentalistas, para realizar acciones de boicot ante emisoras, programas o cualquier expresión de la homosexualidad en las esferas culturales en Estados Unidos. Esta situación se debe a que la incorporación de personajes gays en telenovelas y/o programas de televisión, más que una excepción se ha transformado en una norma. En otro contexto cultural diferente al de Estados Unidos, como lo es China, existe una dualidad en donde personajes gays discretos son incorporados en programas de televisión abierta, pero son censurados a aparecer en producciones cinematográficas. En el caso de El Salvador, donde las temáticas LGBT están vedadas en los medio de comunicación tradicionales como periódicos y canales de televisión, los medios de comunicación electrónicos se han convertido en la forma de dar visibilidad a la 
existencia de una comunidad LGBT y sus demandas políticas.

Sí en la época de Stonewall y la liberación gay, revistas y periódicos fueron los medios para mantener y congregar a la comunidad gay a las causas políticas, ahora es internet y las redes sociales lo que promueve las luchas políticas de la comunidad gay a niveles locales y globales. Convirtiendo el uso de internet como centro de las estrategias para campañas por la igualdad o el caso de los cibermilitantes que contribuyen a difundir noticias sobre graves violaciones a los derechos humanos en países totalitarios.

Este proceso se debe a una situación muy simple, los medios de comunicación y las redes sociales es el lenguaje de las nuevas generaciones de jóvenes, tanto gay como heterosexuales conviven directamente con ellos, y además su impacto es masivo. Por ejemplo en El Salvador, si tomamos en cuenta que la forma de realizar publicidad para la primera marcha del Orgullo gay en 1997, se realiza por medio de fotocopias fijadas en postes del tendido eléctrico y telefónico en la capital logra reunir 250 personas. Ahora en el año 2014, por medio del uso de las redes sociales el trabajo de 20 años de activismo LGBT y el diseño de una imagen de invitación para la Marcha por la Diversidad Sexual logra reunir 7,000 personas de los diferentes departamentos de El Salvador. Los medios de comunicación marcan una diferencia.

La American gay way of life (p. 22) se expresa claramente que es el imaginario de lo gay a nivel global, el cual incorpora un cierto estilo de ropa, música, arte, culinaria, consumo, derecho a casarse, tener hijos, acceder a puestos políticos, incidencia política, creadores de tendencia en la moda, modo de vida, actitud e incluso define un patrón de cuerpo (p. 27, 29, 30, 35, 36, 79,). Pero al mismo tiempo Martel dice que "la vida homosexual es una contrasociedad underground, anticonvencional, arriesgada y maravillosa" (p. 21), así siguiendo esta idea se manifiesta una tensión entre lo global y lo local en el mundo gay, para ello Martel define que "a American gay way of life se globaliza, pero la homosexualidad se vive de forma local" (p. 57). En esta situación podemos encontrar procesos de apropiación y resignificación de conceptos que se distancien de lo gay o lo queer. Así se presenta que en China se reinterpreta la palabra "tongzhi", con una traducción como el orgullo de ser gay o en el argot comunista como "camarada" (p. 113), o "Mithly" en árabe sin connotación peyorativa de "homosexual" o "gay", pero también hace referencia a "idéntico" o "como yo" (p. 250).

Respecto a esas resistencias-apropiaciones de la vida gay a niveles locales, en América Latina presenta diferentes formas de dar un sentido propio a la vida gay. Así en México utiliza la música ranchera, en Cuba la salsa y en Buenos Aires las veladas de tango homo. Estas más que una "revolución simbólica" ( $p$. 56) es una recuperación histórica, ya que el tango en sus orígenes de principios del siglo $\mathrm{XX}$, populares y de mala fama en la zona portuaria, era bailado entre hombres sin importar en esa época la orientación sexual.

El único elemento idenditarío que no entra en resistencias, sino que es una apropiación global es la Rainbow flag (p. 28) como símbolo mundial de la causa LGBT. Esto se debe a la propia construcción de la bandera, creada en Estados Unidos, pero el simbolismo implícito de diversidad y pluralidad la ha convertido en un ícono universal de la comunidad LGBT, que no importando la nacionalidad o diferencias culturales, el sólo hecho de verla ondear en locales, barrios, plazas, playas nos hace sentir un sentimiento de unidad con otras personas que no conocemos, pero sabemos en experiencia propia las violencias que por ser 
disidentes a la norma binaria heterosexual recibimos y compartimos.

Respecto al activismo y recordando el mito de origen de los disturbios del Stonewall Inn en 1969, "la liberación gay empieza con los bares y los clubs, es decir, con el comercio y el mercado" (p. 20). Pero esta liberación adquiere distintos matices de acuerdo al contexto y el tiempo histórico donde se ejecuta. Así luego de los acontecimientos del Stonewall apareció la militancia gay, con características como radical y distribuida en varias células en las grandes ciudades de Estados Unidos. Martel, para el eje cultural occidental contemporáneo construye el concepto de militancia posgay para describir ese proceso descentralizado, pragmático y menos ideológico que algunas organizaciones gays realizan, que le apuestan por el dialogo y no por la provocación para cumplir sus metas y objetivos. Este tipo de militancia no está exento de dificultades, ya que en algunos casos los representantes LGBT, representan al status quo, más que de los intereses de las clases populares y de los márgenes del movimiento gay.

En otros contextos, en donde las organizaciones y la homosexualidad se vive entre "ni prohibidos ni autorizados. Sospechosos, pero tolerados" (p. 114); o como una "red secreta" que no puede formar un movimiento (p. 269), en este tipo de contexto se habla más que de Derechos de los gays, lo que prevalece es la "cultura gay" ( $p$. 117), dado que el "Provocar, militar, hacer proselitismo no es necesariamente la mejor manera de ayudar a los homosexuales en los países musulmanes" (p. 230).

Martel con base a sus observaciones describe cuatro formas de organización social. La primera se puede clasificar como Pregay, donde sus características principales son el estar oculto, mezclado y desapercibido. Cuando este sistema de organización ya no es suficiente, aparece lo propiamente Gay, caracterizado por ser visible, algunas veces radical, anticapitalista y siempre provocador, creando una identidad social, la cual en muchas ocasiones no es tolerada. Cuando la tolerancia aparece se puede decir que es Gayfriendly, donde los homosexuales son visibles y aceptados, siempre y cuando otros marcadores sociales estén de acuerdo con la norma hegemónica: masculinos, clase media, profesionales, blancos, entre otros, así vemos que lo gayfriendly transita entre el elitismo y la exclusión. Por último se encuentra lo Posgay, donde las identidades únicas son desechas y todo está relacionado e integrado.

Por último, Martel cierra su obra con el epílogo: La nueva frontera de los Derechos Humanos, haciendo referencia clara a los derechos humanos de las personas LGBT, los cuales están en disputa en contexto que ejercitan una "homofobia fría" y otra "homofobia caliente" (p. 318) clasificadas según si la violencia que ejerzan es directa (caliente) o estructural (fría). La lucha política por los derechos humanos de personas LGBT está acompañada por fenómenos sociales que están de acuerdo al contexto histórico actual, entre estas diferencias se encuentran el poder de internet y de las redes sociales para convocar y mantener comunicada a la comunidad gay entre sí a nivel global con en lo local. El soft power económico de las comunidades gays $\mathrm{y}$ la valorización cultural de la "identidad" homosexual en medios de comunicación masivos, son aspectos que marcan una oportunidad para hacer un viraje en la historia actual.

Global gay. Cómo la revolución gay está cambiando el mundo, es un insumo que tanto personas interesadas, activistas LGBT y académicos que se dedican al análisis de las cuestiones de género, sexualidad y derechos humanos deben de conocer. Es una obra de lectura fácil, pero al mismo tiempo intensa por las historias de vida que se presentan, las 
resistencias sociales y políticas que se narran y la peligrosidad que existe sobre muchas personas que con el sólo hecho de ejercer su sexualidad pueden estar en riesgo de muerte. Ese riesgo es vivido entre el temor por sus vidas, pero al mismo tiempo por la promesa de llegada un día de sociedades más justas, que acepten a todos y todas sin la realización de ningún proceso de discriminación. 